\title{
Exploring mutual shading and mutual reflection inter-building effects on building energy performance
}

\author{
Yilong Han $^{\mathrm{a}}$, John E. Taylor ${ }^{\mathrm{b}, *}$, Anna Laura Pisello ${ }^{\mathrm{c}}$ \\ ${ }^{a}$ Charles E. Via, Jr. Department of Civil and Environmental Engineering, Virginia Tech, 121 Patton Hall, \\ Blacksburg, VA 24061, USA \\ ${ }^{\mathrm{b}}$ Charles E. Via, Jr. Department of Civil and Environmental Engineering, Virginia Tech, 114 Patton Hall, \\ Blacksburg, VA 24061, USA \\ ${ }^{\mathrm{c}}$ Department of Engineering, University of Perugia, Via G. Duranti 93, 06125 Perugia, Italy
}

\begin{abstract}
The built environment contributes significantly to rapidly growing world energy expenditure and tighter spatial interrelationships can exacerbate this effect in cities. The concept of the Inter-Building Effect (IBE) was introduced to understand the complex mutual impact within spatially proximal buildings. Our research sought to develop a systematic approach to disaggregate and quantify the influence of mutual shading and mutual reflection within a network of buildings. We built an urban building network model and conducted cross-regional simulations under different climatological contexts by examining mutual shading only and mutual reflection only, respectively. We then expanded our investigation by examining two realistic urban contexts in Perugia, Italy. We found the shading effect played a more significant role in terms of impact on energy consumption. The results of the simulations in varying climatological contexts also revealed consistent trends of greater impact on the IBE for shading and reflection in warmer climatic cities. These findings expand and deepen our understanding of inter-building effects and may help in the search to minimize mutual influences between buildings that lead to increases in energy consumption in urban environments.
\end{abstract}

Keywords: Building Networks; Energy Efficiency; Inter-Building Effects; Mutual Reflection; Mutual Shading; Simulation

This paper was presented at the 7th International Conference on Applied Energy (ICAE2015), March 28-31, 2015, Abu Dhabi, UAE (Original paper title: "Disaggregate Analysis of the Inter-Building Effect in a Dense Urban Context" and Paper No.: 334)

${ }^{*}$ Corresponding author. Tel.: +1 540231 0972; Fax: +1 5402317532.

E-mail addresses: ylhan@vt.edu (Yilong Han), jet@vt.edu (John E. Taylor), pisello@crbnet.it (Anna Laura Pisello) 


\section{Introduction and Background}

Rapidly growing world energy expenditure has raised global concerns and became a central topic of research and public debate over the last several decades. Cities represent the highest concentration of energy use [1]. Buildings alone account for as much as $32 \%$ of total final energy consumption and nearly $40 \%$ of primary energy consumption [2]. To address building energy consumption, numerous research efforts have focused on how to achieve a more sustainable built environment from perspectives such as renewable energy [3, 4], adaptive building envelopes and materials [5-7], occupant efficiency [8, 9], advanced building information technologies [10, 11] and building automation systems [12, 13], sustainable rating strategies $[14,15]$ and energy policies [16], among others. Urbanization-referred as the migration of rural dwellers toward towns, cities and megacities for the promise of a better life-is creating profound effects in the urban environment, including; the quality of urban air, urban temperature, energy consumption and water supply, pollution and waste products, loss of bio-diversity, conversion of agricultural to developed land, etc. [17]. A recent report from the United Nations projected the population in urban areas to reach 6.3 billion in $2050,72 \%$ greater than the 3.6 billion urban dwellers in 2011 [18]. Urban built settings are evolving toward much tighter spatial interrelationships, which could exacerbate urban energy consumption, and also influence the surrounding microenvironment and microclimate. The motivation of this research is to examine and deepen our understanding of interbuilding relationships in dense urban settings resulting from urbanization and the related impacts on building energy consumption.

Urban morphology — characterized by building density, size, height, orientation, and layout— causes considerable variations in the local environment. Urban microclimates affect a building's performance in terms of energy consumption and indoor living environment, while buildings affect the urban microclimate within their building networks [19-22]. Early research largely focused on the energy behavior attributed to individual buildings to understand and optimize the energy efficiency of an individual building by describing indoor thermal behavior, energy consumption, and building envelope 
features. However, to treat buildings as stand-alone entities does not accurately represent a building's energy performance since it does not consider the nearby buildings which could exert a mutual influence on thermal dynamics. One example is that reflective envelopes could reflect daylight to the neighboring buildings and surrounding areas and create problems such as glare and overheating, which may result in visual and thermal discomfort to building occupants [23]. Thus, building networks and urban street canopies should be taken into consideration, and have drawn attention by building researchers to holistically understand energy issues. He et al. [24] studied the impact of the local outdoor environment to building thermal-energy behavior, indicating that it is not sufficient enough to assess a building's energy dynamics solely based on building features. To evaluate solar rights and shading requirements in an urban environment, Shaviv and Yezioro [25] developed a CAD tool that can analyze the mutual shading between buildings and surrounding objects, such as trees, and it was later extended by Li [26] to study the daylighting and energy implications from nearby obstructing buildings. Golany [27] built upon this, bringing an urban design view of the relationship between urban design morphology and the thermal performance of the city concerning street orientation, building geometry and urban proportions. Taking the idea of urban design morphology to the next step, Conceição António et al. [28] proposed an approach on the optimal placement of buildings that favors the use of solar energy.

To understand the complex interactions within spatially proximal urban building networks, the concept of the Inter-Building Effect (IBE) has been introduced and further studied over the last several years [29-31]. Pisello et al. [30] employed IBE indexes to demonstrate the interrelationship between buildings within building networks which could result in substantial inaccuracies (up to $42 \%$ in summer, and up to $22 \%$ in winter) of energy consumption predictions for space heating and space cooling. The research also revealed that the buildings' energy performance can be significantly impacted by surrounding buildings through mutual reflection and mutual shading [30]. Thus, in order to accurately predict the energy performance of a single building, the IBE created by the spatially proximal buildings should be considered. IBE research was later expanded to examine primary lighting energy consumption using daylight analysis and through the use of empirical data for model calibration [29]. Higher values of 
the IBE indexes were found for the lighting energy consumption, indicating lighting is also impacted by surrounding buildings within inter-building contexts. With foreseeable urbanization in the next several decades, tighter spatial interrelationships between buildings in urban settings will exacerbate the IBE and this necessitates a more nuanced analysis of its effects. Although shading and reflection have been discussed as two essential components of the IBE [29, 30], previous research has largely considered the IBE as a monolithic effect across building networks. More research is needed to disaggregate the impact in order to explore which factors may be largely dependent on the local climatic environment and which could be addressed separately through urban planning and building designs.

The research presented in this paper builds upon previous IBE efforts [29-31] concerning the study of energy and thermal behavior of buildings in a dense urban context to further analyze and understand the effect of mutual impact by the IBE in a micro-urban environment. Our objective is to develop a procedure to separately assess the complex interactions, i.e. mutual shading and mutual reflection, that make up the IBE. Through comparative simulation and analysis, we sought to disaggregate and quantify the influence of mutual shading and mutual reflection with respect to space heating, space cooling energy and lighting energy consumption within a network of buildings in urban contexts. The findings of a more nuanced analysis of IBE could lead to better understanding the inter-building thermalenergy relationship and lead solutions to mitigate the negative impact of the IBE in urban microenvironments.

\section{Methodology}

\subsection{Simulating the IBE in a dynamic environment}

Simulation tools offer powerful functionalities to predict and improve building energy consumption for both research and design purposes. Of current main stream simulation environment and platforms, EnergyPlus [32], an energy analysis and thermal load simulation engine distributed by the U.S. Department of Energy, has become a popular building energy performance simulation owing to its sophisticated and validated functions. It was utilized for previous IBE research and dynamic building 
network analyses [29-31].Early IBE simulation efforts were conducted based on a realistic physical urban block in New York State [30]. The research demonstrated that buildings could mutually influence the energy dynamics of near buildings, especially for cooling and heating, and cause substantial energy prediction inaccuracies over the course of a year. Later research further investigated the energy discrepancies in lighting and validated the IBE, as an important effect to be modeled in situations where buildings are surrounded by other nearby buildings [29]. Experiment and empirical data were used to calibrate and verify the simulation work.

Inherited from previous IBE research, we first developed a procedure to separately access the shading effect and the reflection effect in EnergyPlus which is described in Section 3.2. With that, we built a hypothetical nine-building network model to analyze the thermal-energy behavior of the middle control building with combined IBE, IBE without shading, and IBE without reflection, respectively, under different climatological conditions. This is described in Section 3.3. We then examined two realistic urban dense contexts located in Perugia, Italy using the same procedure for this disaggregate analysis. This is described in Section 3.4.

\subsection{Procedure for disaggregating shading and reflection from the IBE}

Shading and reflection have been evidenced as major contributors that make up the IBE [29, 30]. Therefore, we sought to develop a procedure to disaggregate mutual shading and mutual reflection and assess them separately in the numerical simulation and analysis. The control building was modeled with heat-transferring surfaces and its energy was monitored over the course of the simulation. Shading surfaces, an essential geometric element for shading and reflection in the EnergyPlus environment, were used to model neighboring buildings within the studied building networks, to satisfy our simulation needs and avoid of excessive input and prohibitive running times for zone calculations.

The EnergyPlus simulation environment uses a ray-tracing method to account for reflections in solar gain and daylight calculation [33]. When solar radiation is diffusely reflected onto each of a 
buildings' exterior surfaces, the "receiving surfaces" will generate a set of rays proceeding into the outward hemisphere at each receiving point, and determine whether each ray hits the sky, ground, or an obstruction. The radiance at the hit point from the reflection of incident beam is calculated, and contributes to the radiance of its receiving surface. The setting in the field of "Solar Distribution" determines how EnergyPlus treats solar radiation that is reflected from exterior surfaces and then strikes the building [33]. It has five parameters, including; "MinimalShadowing", "FullExterior", "FullInteriorAndExterior", "FullExteriorWithReflections", and "FullInteriorAndExteriorWithReflections". This functionality enables us to test mutual shading alone by eliminating reflection calculations. Such application is usually utilized for less-detailed schematic analysis because reflection calculations can be time-consuming and error-prone. From this, shadow patterns on the control building's exterior surface caused by neighboring buildings are computed, and the reflected solar radiation from its surroundings is neglected.

The effects of shading from the surrounding environment are computed using detailed surface geometry. For shading surfaces, the "bi-directional" shading effect can be manipulated by changing the value of "Transmittance Schedule" with a range from 0.0 to 1.0 [33]. This schedule can be used to allow daily or seasonal transmittance change of a shading element such as deciduous trees that have higher transmittance in winter and lower in summer when their leaves are fully extended. The default transmittance value is 0.0 which means the shading surface is opaque at all times. However, setting it to 1.0 can make the surface transparent and yet keep the reflective properties intact to test reflection when the "WithReflections" option is chosen for "Solar Distribution" [33, 34]. In this way, the shading effect is excluded within the inter-building environment.

With the approach to turn on and off shading and reflection features by manipulating the shading surfaces in the dynamic simulation environment, we could then create different urban micro-environment within building networks, i.e. with combined IBE, IBE without reflection effect, and IBE without shading effect, and test how different scenarios would influence the energy behavior of the control building. It is 
important to note that for all instances, the control building remained the same to solely test the energy impact caused by the changes we made to the urban microenvironment settings. We implemented OpenStudio [35], a graphical third-party application developed by the National Renewable Energy Laboratory (NREL) to support whole building energy modeling, to visualize and to build precise models in a SketchUp interface.

\subsection{Case Study 1: Hypothetical urban building network}

We built a hypothetical building network for the first case study as illustrated in Figure 1. It is a ninebuilding block that contains one reference building in the center of the building network and eight surrounding shading-surface buildings. The morphology of each building was the same for all buildings within the network. The control building was modeled as a three-story commercial building with a square shape of 10 meters per side. The distance between buildings was set to be 5.25 meters (Height/Width ratio= 2) for both the East-West direction and the North-South direction. For the credibility of the simulation results, we also utilized information about construction materials, temperature set-points, and schedules for lighting, equipment, and occupants from previously published IBE research [29, 30]. Some key parameters are listed as below. The opaque envelope of the reference building consists of external brickwork $(0.10 \mathrm{~m})$, XPS extruded polystyrene $(0.080 \mathrm{~m})$, lightweight concrete block $(0.010 \mathrm{~m})$, and internal gypsum plasterboard $(0.013 \mathrm{~m})$, with a global thermal transmittance of $0.314 \mathrm{~W} / \mathrm{m}^{2} \mathrm{~K}$. The roof contains an internal layer of plasterboard $(0.015 \mathrm{~m})$, an air gap and roof structure $(0.20 \mathrm{~m})$, glass wool insulation $(0.15 \mathrm{~m})$ and asphalt $(0.010 \mathrm{~m})$, with a global thermal transmittance of $0.250 \mathrm{~W} / \mathrm{m}^{2} \mathrm{~K}$. The internal ceiling consists of gypsum plasterboard $(0.015 \mathrm{~m})$, lightweight cast concrete $(0.10 \mathrm{~m})$, elastomeric foam $(0.005 \mathrm{~m})$, and lightweight plywood $(0.020 \mathrm{~m})$, with a global thermal transmittance of $1.122 \mathrm{~W} / \mathrm{m}^{2} \mathrm{~K}$. The ground floor includes wooden flooring $(0.020 \mathrm{~m})$, mineral wool $(0.15 \mathrm{~m})$, floor structure $(0.20 \mathrm{~m})$, and external rendering $(0.025 \mathrm{~m})$, and it represents a global transmittance of $0.246 \mathrm{~W} / \mathrm{m}^{2} \mathrm{~K}$. The external windows are modeled as double clear glass panes $(6 \mathrm{~mm}-6 \mathrm{~mm}$ with $6 \mathrm{~mm}$ air). The main working hour 
schedule is from $8 \mathrm{am}$ to $6 \mathrm{pm}$ during weekdays. The internal heat gain from people and lighting are $6 \mathrm{~W} / \mathrm{m}^{2}$ and $10 \mathrm{~W} / \mathrm{m}^{2}$, respectively.

Insert Figure 1 about here

Early IBE research found that IBE effects vary by climatological context [8, 30, 31]. Therefore, three typical and climatologically distinct U.S. cities, Miami, FL, Minneapolis, MN, and Washington, D.C. were selected for a pilot cross-regional analysis. Miami and Minneapolis represent the extreme climate conditions where heating and cooling loads are largely concerned, while Washington, D.C. has a distinctive and roughly equal length seasons as a typical temperate city. Using the weather profile of each city, several case studies were conducted to test the IBE without reflection, the IBE without shading, and the combined IBE, respectively. We then expanded our analysis to include a total of eight cities covering all six climate zones in the U.S. containing populous cities. For all instances, the control building remained the same and was being monitored in terms of energy and thermal performance over the course of the simulation period. Monthly and annual results were reported, analyzed, and discussed in the following sections. The diffuse solar reflectance of the exterior building envelopes was set to $40 \%$ with ground reflectance set to $20 \%$.

\subsection{Case Study 2: Real urban building networks in Italy}

To examine the shading/reflection effect in a more realistic urban morphology characterization, we chose to study two distinct urban building networks in Perugia, Italy. Perugia is a city in central Italy with a temperate climate that has not only severe winter but also hot summer climatological conditions. The choice of the two representative urban contexts [36] were guided by both urban and technicalarchitectural reasons. The two cases are illustrated in Figure 2. The urban context (a) located at the historical center of the city was characterized by a Middle Ages layout representing a very dense urban 
context (Height/Width ratio>4). The reference building was a four-story XVI century residential building. The opaque envelope of the reference building consists of two layers of medium weight masonry $(0.20 m+0.15 m)$ and an inner layer gypsum plastering $(0.02 m)$, with a global thermal transmittance of $0.949 \mathrm{~W} / \mathrm{m}^{2} \mathrm{~K}$. The other context (b) is located at the close periphery of the city, where many residential buildings were built around 1960-1970, before the enforcement of the first Italian building energy efficiency regulation. The reference building is a five-story residential building, and the opaque envelope consists of an external layer of cement plaster $(0.02 \mathrm{~m})$, an innermost layer of gypsum plastering $(0.15 \mathrm{~m})$, and two layers of brick $(0.18 \mathrm{~m}+0.12 \mathrm{~m})$ separated by an air gap $(0.05 \mathrm{~m})$, with a global thermal transmittance of $1.202 \mathrm{~W} / \mathrm{m}^{2} \mathrm{~K}$. The glazing systems were modeled as double clear glass panes $(6 \mathrm{~mm}$ $6 \mathrm{~mm}$ with $13 \mathrm{~mm}$ air) for both the urban context (a) and (b). The windows have a global thermal transmittance of $2.665 \mathrm{~W} / \mathrm{m}^{2} \mathrm{~K}$ and a direct solar transmission of 0.604 . For each context, the representative building was selected based on architectural topology, envelope material, and thermal energy performance. Each reference building is circled in Figure 2 (a) and (b). For the two case study models, an iterative calibration method and validation process have been implemented by the integrated analysis of mean bias error and the variation of the roof mean squared error in terms of energy use and indoor thermal behavior [36]. The majority of Italian residential buildings are made of non-insulted envelopes, which makes this study more representative of the built Italian panorama.

Insert Figure 2 about here 


\section{Analysis and Results}

\subsection{Case Study 1: Control building's energy behavior within hypothetical building network}

In the first case study, year round energy analysis was conducted. Annual results of control building energy consumption including lighting, space heating, space cooling, and total primary energy are reported in Table 1, Table 2, and Table 3 for Miami, FL, Washington, D.C., and Minneapolis, MN, respectively. In the tables: "IBE" stands for the combined IBE situation as baseline values; "IBE w/o R" represents the results when reflection is turned off for a comparable simulation; similarly, "IBE w/o S" denotes an inter-building environment without considering the shading effect. In the rows of "IBE w/o R" and "IBE w/o S", variation percentages were also calculated according to the baseline combined IBE value. A “+” sign indicates an increase in energy usage while a "-" sign means that savings would occur for that particular situation, indicating less energy is being used. For instance, the " $+34.1 \%$ " in Table 1 indicates an increase of 34.1 percent for primary cooling energy consumption required for the reference building within the building network under the weather profile of Miami without the mutual shading effect.

Insert Table 1 about here

Insert Table 2 about here

Insert Table 3 about here 
Our first observation from Tables 1-3 is that the patterns of the "+" and "-" signs stay the same across the three simulated cites, indicating that for different climatic regions, removing the reflection effect could increase the control building's lighting and heating energy consumption while decreasing its cooling loads. Conversely, lighting and heating loads drop and at the same time cooling loads climb when the shading effect is disaggregated (in rows of simulation type "IBE w/o S"). However, we notice that, for all instances, the shading effect plays a more significant role in terms of the impact on energy consumption compared to the reflection effect. This resulted in substantial variations of the control buildings' energy consumption when the shading effect was disaggregated from the IBE. For example, in Washington D.C. (Table 2), the absolute values of the variation percentage of the lighting, heating, cooling and total primary energy consumption are $26.3 \%, 53.6 \%$, and $12.7 \%$, respectively, when the shading effect is turned off, more than four times the percentages for simulations without reflection (5.0\%, $10.0 \%$, and $2.2 \%)$.

The results of total energy consumption in varying climatological contexts also revealed consistent trends of greater impact on the IBE for shading and reflection in warmer climatic cities. Miami has a higher percentage " $+30.1 \%$ " for simulation without the shading effect, while Washington, D.C. and Minneapolis amount to " $+12.7 \%$ " and " $+4.2 \%$ ", respectively. Similarly, when reflection is disaggregated, Miami has a "-6.0\%" in total energy consumption which is a higher percentage compared to Washington, D.C. ("-2.2\%") and Minneapolis (“-0.7\%").

We then further broke down annual energy consumption to the monthly level for a more nuanced analysis. The results are tabulated in Table 4. This indicates in which month disaggregation would positively or negatively impact a building's energy behavior for a particular city. Favorable results (with negative variation percentage number) for each month are indicated with a grey background. In Miami, taking off reflection always causes less energy usage all year owing to its tropical weather condition, which has a long summertime and a mild winter. On the other hand, seven months (April, May, June, July, August, September, and October) benefit from shading while reflection is favorable to the other five months (January, February, March, November, and December) for the case of Washington, D.C. with 
roughly four equal length and distinct seasons. In Minneapolis, which is characterized by a long, cold winter and a hot, humid summer, the control building has better energy performance in five months (May, June, July, August, and September) without reflection and seven months (January, February, March, April, October, November, and December) without shading.

Insert Table 4 about here

In order to deepen our analyses of these impacts within the studied building network, we expanded to a more thorough cross-regional energy analysis of eight cities in the U.S. [8, 37]. The selected eight populous cities cover all four U.S. census regions (Northeast, Midwest, South, West), and zones 1-6 of the eight climate zones defined by International Energy Conservation Code where zone 7 and 8 represent the coldest areas in the United States with no populous cities. They are Los Angeles, CA (zone 2) and San Francisco, CA (zone 3) from the West Region; Chicago, IL (zone 5) and Minneapolis, MN (zone 6) from the Midwest Region; New York, NY (zone 4) and Boston, MA (zone 5) from the Northeast Region; and Houston, TX (zone 2) and Miami, FL (zone 1) from the South Region.

Insert Table 5 about here

The eight-city cross regional analysis is reported in Table 5 and contains the total energy consumption (including space heating, space cooling and lighting) and the corresponding variation percentage for the IBE without reflection and the IBE without shading. The numbers in this table are consistent with our previous results and further support our observation in terms of the pattern of energy consumption change (“+” "-" energy impact) and the dominant factor (shading effect) for this hypothetical building network. The four cities from the Midwest region and the Northeast region have less energy variations when shading or reflection is disaggregated from the IBE, especially for the coldest 
northernmost Minneapolis, MN and Boston, MA which both have less than $1 \%$ and $6 \%$ when the reflection factor and shading factor are turned off, respectively. Although we identified a larger variation and IBE impact in the hottest South region, the most significant change of energy consumption actually occurs in the West region where the energy loads in San Francisco, CA and Los Angeles, CA drop as much as 10.7 percent when the mutual reflection effect is not considered, and increase as much as 60 percentage without mutual shading within the studied environment. This could be due to the solar positions and relatively less baseline energy consumption values in the West region. Overall, this expanded cross regional analysis supported the trends we identified in Miami, FL, Washington, D.C., and Minneapolis, MN.

\subsection{Case Study 2: Reference building's energy behavior within two dense urban contexts in Perugia, Italy}

In Case Study 2, two representative urban contexts in Perugia, Italy were selected to study the shading/reflection effect in realistic urban building networks. The urban context (a) is an extreme dense area in the historical center of Perugia; the other context (b) represents a neighborhood at the close periphery of the city. Year-round analysis was conducted under the local weather profile of the temperate city, and the annual results of space heating energy consumption and space cooling energy consumption are reported in Table 6 and Table 7 for context (a) and (b), respectively. The same notations ("IBE", "IBE w/o R" and "IBE w/o S") and symbols ("+" and "-") are used to indicate the different simulation scenarios and results in the tables.

Insert Table 6 about here

Insert Table 7 about here 
The patterns of "+" “-” signs remain identical to our hypothetical building network analysis presented in Table 6 and 7, indicating the shading effect contributes to lighting and heating energy consumption while the reflection effect increases cooling energy within building networks. This supports our earlier assertions regarding shading and reflection impact on building primary energy consumption. For both cases in Perugia that have distinct urban contexts, the disaggregation of the shading effect results in larger variations of the studied buildings' energy consumption. This again supports our assertion that the shading effect ("IBE w/o S") has a larger impact compared to the reflection effect ("IBE w/o R") in each individual energy component (lighting, heating, and cooling). Shading dominates more in higher density urban blocks that have significant amounts of energy variation for lighting, space heating and space cooling as the results showed in case (a).

However, this case study showed more complicated outcomes could occur in a real life urban environment. We noticed an unusually high amount of cooling energy increase $(237.6 \%)$ when shading effect was eliminated in the Perugia urban context (a). The interpretation of this number could be the low baseline value of cooling energy consumption $(600.1 \mathrm{kWh})$ as well as the substantial impact due to shading in high-density contexts (extreme high height/width ratio in the neighbourhood). Despite the fact that the reference building in the urban context (b) is larger than that in the urban context (a) and consumed nearly five times more in terms of total energy consumption, we also observed that the lighting surpassed cooling as the second largest energy consumption factor in both cases. This realistic urban building network case study resulted in different building energy behavior through disaggregate analysis.

\section{Discussion}

A great deal of research effort has focused on reducing building energy consumption and achieving a more sustainable built environment [23-27]. However, the majority of this research treats each building as a stand-alone entity without considering the neighboring buildings that may substantially influence energy consumption. Recent research has demonstrated that one building's energy performance is influenced by its nearby micro-environment, and the concept of IBE has been introduced and discussed 
within spatially-proximal building networks [29-31]. Although mutual shading and mutual reflection have been identified as two primary components that make up the IBE, such impact has to date been considered as a monolithic effect. Given the important IBE implications for urban design and building and environmental energy assessment, the research presented in this paper contributes to the discussion by developing a systematic approach in a dynamic simulation environment to disaggregate the separate and distinct impact from reflection and shading for a more nuanced analysis. Through cross-regional analysis of our hypothetical building network and realistic urban context case studies in a temperate city in Italy, we found shading to contribute to increased heating and lighting loads while reflection increased cooling energy required for spatially-proximal buildings in all scenarios. We identified a consistent trend indicating that when mutual reflection is turned off, shading has a relatively larger contribution to IBE within building networks. In our hypothetical building network study, we found the IBE to have a larger impact in warmer areas, with variation percentage from baseline use always being the largest in the tropical city of Miami, and the smallest percentage was for Minneapolis, the coldest metropolitan city. We expanded our analysis to more cities covering different climate zones, and interestingly found that two cities in the West region-San Francisco, CA and Los Angeles, CA-have the most significant change of energy use when shading or reflection is disaggregated out of the analysis. One reason for this could be the lower baseline value of the energy consumption in those two cities that have neither severe winters nor summers. The solar position could also be another important factor of IBE. The angle of incident beam due the azimuth and the altitude of the sun could influence the impact of mutual shading and mutual reflection within spatially-proximal buildings. In general, we observed larger variations of the energy impact in warmer areas when shading and reflection are disaggregated within a building network. Thus, it extends previous studies on the shading effect $[25,26]$ and suggests that future research on practical measures should focus more on shading interventions, especially in cities under warmer climatic conditions.

We further broke down our analysis to a monthly basis. This revealed that the contribution of reflection and shading varies on a month-to-month basis. Building energy performance in warmer 
climatic cities like Miami with a longer summer, longer daylight time and more demand for cooling energy would benefit when the reflection effect is mitigated all year round. However, in the cities that have four distinct seasons, reflection and shading could be either detrimental or favorable for different months. The impact is closely related to the geographical location and weather conditions. From the simulated results, general recommendations can be provided for urban planning and building designs, which could help promote sustainable and energy-responsive building networks. By implementing optical features to building envelopes [31], we may be able to control the negative effect of reflection in tropical cities. On the other hand, thermal storage techniques [38] could help shift peak energy loads neutralizing the month-to-month mutual impact variations. These findings, taken together, expand and deepen our understanding of the IBE and may help in the search to minimize mutual influences between buildings that lead to increases in energy consumption in urban environments.

The intent of the two cases in Italy is not only to interpret the IBE disaggregate analysis with respect to urban morphology characterization in a realistic urban morphology life, but also to investigate the impact of increasing urban density level. By employing the disaggregate methodology to examine the variances of year-round energy performance of reference buildings in two distinct Italian urban contexts, we found support for our hypothetical model analyses that mutual shading always contributes to increases in heating and lighting loads and mutual reflection contributes to increased cooling energy consumption. Different and more complicated building energy behavior was observed through disaggregate analysis. The shading effect, as the larger impact factor of IBE, is more dominated in higher urban blocks. The Italy case study further demonstrates the urban building networks' morphology and the importance of local climatic context impact for IBE research. It also contributes how such analyses enable the planning of more efficient building networks in urban practical applications. We demonstrated that primary building energy consumption can be influenced by the complex and dynamic urban micro-environment. Thus, urban building designs should adopt a more holistic consideration of the building network in which a designed building will be situated. There is the potential to introduce shading design interventions and/or reflection design interventions - depending on the climatological context - that will positively 
impact the cooling, heating, and lighting energy consumption of the building being designed, as well as possibly positively impacting neighboring buildings.

The purpose of this research was to separately assess mutual shading and mutual reflection for a better understanding of the complex inter-building relationships resulting from urbanization. EnergyPlus has become a popular and reliable research tool for building energy simulation and empirical studies have been used to calibrate and validate the simulation results, particularly for the heating and cooling energy consumption $[30,34,39]$. The model information used in this research was built upon previous research $[30,31]$ and an ideal loads air system setting was implemented without considering the mechanical efficiency. Through cross-regional comparison, the results provide us a more explicit understanding of inter-building relationship. In executing the simulation, a human-based check was conducted to ensure the accuracy of the dynamic simulation result. No exception output or process warning were observed over the course of the simulation. Nevertheless, the modeling and simulation efforts resulted in some limitations. The network of buildings was nine buildings for the hypothetical building network disaggregate analysis to keep the research scope reasonable but sufficiently detailed to develop the proposed approach. The realistic case study was limited to one city with certain weather condition and two different urban contexts. We observed that real life cases could lead to peculiar outcomes. It is possible that a more complicated outcome due to different or larger urban scales may exist and, if so, were neglected in the research. In future research, we will examine scaled building network models empirically with different orientations and building envelope properties. We will use thermal sensor data combined with weather station data to further validate the simulation results. With optimization measures drawing more attention in building energy research recently $[28,40]$, future research should address these limitations as well as seek out measures to mitigate the negative impacts of the IBE and optimal placement of network buildings considering local climatological contexts. 


\section{Conclusions}

The research in this paper built upon and extended previous IBE approaches [29-31] that studied energy consumption predictions in dense urban building networks, and continued exploring the complex and dynamic urban microclimates [19-21]. It contributes a systematic approach to separately assess the complex interactions that make up the IBE. By manipulating the building envelopes, we disaggregated and quantified the influence of mutual shading and mutual reflection within a network of buildings. Cross-regional case studies of a hypothetical urban building network were established and simulated in the dynamic EnergyPlus environment for energy assessments, followed by two realistic urban contexts case studies in Perugia, Italy. The findings of energy consumption in the reference building demonstrate that shading has a relatively larger individual impact compared to reflection within the building's microenvironment. We found shading to contribute to increased heating and lighting loads while reflection increased cooling energy required for spatially-proximal buildings. Although we found the discrepancies of energy use due to disaggregate analysis to largely depend on the local climatological conditions, the results revealed consistent trends of greater impact on the IBE for shading and reflection in warmer climatic cities. Tropical cities that have high demand for cooling energy would benefit when reflection is mitigated all year round, while such impact in other cities is closely related to geographical location and climatological contexts. Understanding the distinct impacts of shading and reflection and addressing them separately could lead to optimization of the thermal-energy performance within spatially proximal buildings, and will become increasingly important as urbanization creates increasingly dense urban environments in cities around the world.

\section{Acknowledgments}

This material is based in part upon work supported by the National Science Foundation under Grant No. 1142379 and by the BioBuild Virginia Tech Interdisciplinary Graduate Education Program grant. Any opinions, findings, and conclusions or recommendations expressed in this material are those of the 
authors and do not necessarily reflect the view of the National Science Foundation or the BioBuild Interdisciplinary Graduate Education Program. The authors' acknowledgments are due to H2CU (Honors Center of Italian Universities) for supporting the international cooperation among the authors.

\section{References}

[1] S.C.M. Hui, Low energy building design in high density urban cities, Renewable Energy, 24 (3-4) (2001) 627-640.

[2] International Energy Agency, Energy Efficiency, in, 2013.

[3] D. Connolly, H. Lund, B.V. Mathiesen, M. Leahy, The first step towards a $100 \%$ renewable energy-system for Ireland, Appl. Energy, 88 (2) (2011) 502-507.

[4] M. Pehnt, Dynamic life cycle assessment (LCA) of renewable energy technologies, Renewable Energy, 31 (1) (2006) 55-71.

[5] R.C.G.M. Loonen, M. Trčka, D. Cóstola, J.L.M. Hensen, Climate adaptive building shells: State-of-the-art and future challenges, Renewable Sustainable Energy Rev., 25 (0) (2013) 483493.

[6] L.G. Caldas, L.K. Norford, Genetic algorithms for optimization of building envelopes and the design and control of HVAC systems, J. Sol. Energy Eng., 125 (3) (2003) 343-351.

[7] U. Berardi, A. GhaffarianHoseini, A. GhaffarianHoseini, State-of-the-art analysis of the environmental benefits of green roofs, Appl. Energy, 115 (2014) 411-428.

[8] X. Xu, P.J. Culligan, J.E. Taylor, Energy Saving Alignment Strategy: Achieving energy efficiency in urban buildings by matching occupant temperature preferences with a building's indoor thermal environment, Appl. Energy, 123 (2014) 209-219.

[9] R.K. Jain, J.E. Taylor, G. Peschiera, Assessing eco-feedback interface usage and design to drive energy efficiency in buildings, Energy Build., 48 (2012) 8-17.

[10] S. Azhar, Building information modeling (BIM): Trends, benefits, risks, and challenges for the AEC industry, Leadersh. Manage. Eng., 11 (3) (2011) 241-252.

[11] T. Hong, S. Chou, T. Bong, Building simulation: an overview of developments and information sources, Build. Environ., 35 (4) (2000) 347-361.

[12] H. Dibowski, J. Ploennigs, K. Kabitzsch, Automated design of building automation systems, Industrial Electronics, IEEE Transactions on, 57 (11) (2010) 3606-3613.

[13] J. Široký, F. Oldewurtel, J. Cigler, S. Prívara, Experimental analysis of model predictive control for an energy efficient building heating system, Appl. Energy, 88 (9) (2011) 3079-3087.

[14] U.G.B. Council, LEED rating systems, Retrieved September, 11 (2008) 2008.

[15] S. Azhar, W.A. Carlton, D. Olsen, I. Ahmad, Building information modeling for sustainable design and LEED® rating analysis, Autom. Constr., 20 (2) (2011) 217-224.

[16] S. Jacobsson, V. Lauber, The politics and policy of energy system transformationexplaining the German diffusion of renewable energy technology, Energy policy, 34 (3) (2006) 256-276.

[17] M. Santamouris, Energy and climate in the urban built environment, Routledge, 2013.

[18] UN DESA, World Urbanization Prospects, the 2011 Revision, in, United Nations, 2011.

[19] R. Yao, K. Steemers, Urban Microclimates and Simulation, in, 2013, pp. 77-97. 
[20] F.S. de la Flor, S.A. Domínguez, Modelling microclimate in urban environments and assessing its influence on the performance of surrounding buildings, Energy Build., 36 (5) (2004) 403-413.

[21] E. Krüger, D. Pearlmutter, F. Rasia, Evaluating the impact of canyon geometry and orientation on cooling loads in a high-mass building in a hot dry environment, Appl. Energy, 87 (6) (2010) 2068-2078.

[22] S.K.H. Chow, D.H.W. Li, E.W.M. Lee, J.C. Lam, Analysis and prediction of daylighting and energy performance in atrium spaces using daylight-linked lighting controls, Appl. Energy, 112 (2013) 1016-1024.

[23] X. Yang, L. Grobe, W. Stephen, Simulation of reflected daylight from building envelopes, in: Proceedings of BS2013: 13th Conference of International Building Performance Simulation Association, 2013.

[24] J. He, A. Hoyano, T. Asawa, A numerical simulation tool for predicting the impact of outdoor thermal environment on building energy performance, Appl. Energy, 86 (9) (2009) 1596-1605.

[25] E. Shaviv, A. Yezioro, Analyzing mutual shading among buildings, Sol. Energy, 59 (1-3) (1997) 83-88.

[26] D.H.W. Li, S.L. Wong, Daylighting and energy implications due to shading effects from nearby buildings, Appl. Energy, 84 (12) (2007) 1199-1209.

[27] G.S. Golany, Urban design morphology and thermal performance, Atmos. Environ., 30 (3) (1996) 455-465.

[28] C.A. Conceição António, J.B. Monteiro, C.F. Afonso, Optimal topology of urban buildings for maximization of annual solar irradiation availability using a genetic algorithm, Appl. Therm. Eng., 73 (1) (2014) 422-435.

[29] A.L. Pisello, V.L. Castaldo, J.E. Taylor, F. Cotana, Expanding Inter-Building Effect modeling to examine primary energy for lighting, Energy Build., 76 (0) (2014) 513-523. [30] A.L. Pisello, J.E. Taylor, X. Xu, F. Cotana, Inter-building effect: Simulating the impact of a network of buildings on the accuracy of building energy performance predictions, Build. Environ., 58 (0) (2012) 37-45.

[31] Y. Han, J.E. Taylor, A.L. Pisello, Toward mitigating urban heat island effects: Investigating the thermal-energy impact of bio-inspired retro-reflective building envelopes in dense urban settings, Energy Build., 102 (2015) 380-389.

[32] D.B. Crawley, L.K. Lawrie, F.C. Winkelmann, W.F. Buhl, Y.J. Huang, C.O. Pedersen, R.K. Strand, R.J. Liesen, D.E. Fisher, M.J. Witte, EnergyPlus: creating a new-generation building energy simulation program, Energy Build., 33 (4) (2001) 319-331.

[33] L. UIUC, EnergyPlus engineering reference: the reference to EnergyPlus calculations, US Department of Energy, (2005).

[34] P.G. Ellis, P.A. Torcellini, Simulating tall buildings using EnergyPlus, in: International IBPSA Conference, 2005, pp. 279-286.

[35] R. Guglielmetti, D. Macumber, N. Long, OpenStudio: an open source integrated analysis platform, in: Proceedings of the 12th Conference of International Building Performance Simulation Association, 2011.

[36] A.L. Pisello, J.E. Taylor, F. Cotana, Simulating the effect of urban morphology on indoor thermal behavior: an Italian case study, in: Proceedings of the 2013 Winter Simulation Conference: Simulation: Making Decisions in a Complex World, IEEE Press, 2013, pp. 20082019. 
[37] U.S. Census Bureau, (2011).

[38] F. Ascione, N. Bianco, R.F. De Masi, F. de' Rossi, G.P. Vanoli, Energy refurbishment of existing buildings through the use of phase change materials: Energy savings and indoor comfort in the cooling season, Appl. Energy, 113 (2014) 990-1007.

[39] X. Xu, P.J. Culligan, J.E. Taylor, Energy Saving Alignment Strategy: Achieving energy efficiency in urban buildings by matching occupant temperature preferences with a building's indoor thermal environment, Appl. Energy, 123 (0) (2014) 209-219.

[40] E. Rodrigues, A.R. Gaspar, Á. Gomes, Improving thermal performance of automatically generated floor plans using a geometric variable sequential optimization procedure, Appl.

Energy, 132 (2014) 200-215. 


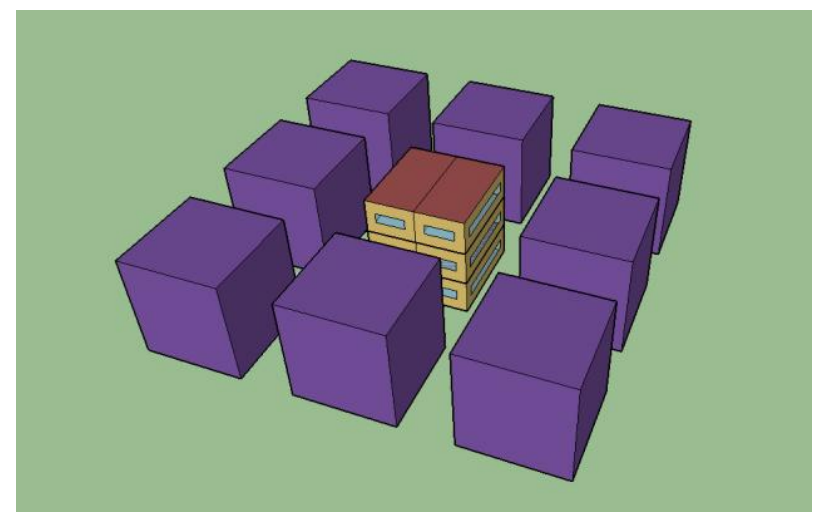


(a)

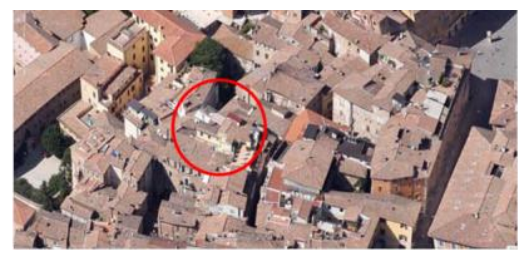

(b)

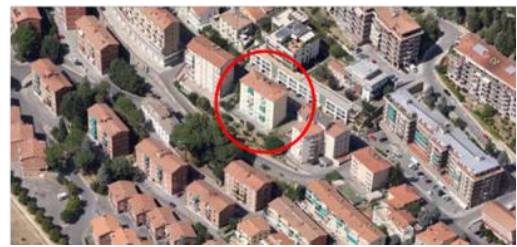




\section{Table(s) with Caption(s)}

Table 1

Control building's energy consumption in Miami, FL

\begin{tabular}{|c|c|c|c|c|c|c|c|c|}
\hline $\begin{array}{c}\text { Simulation } \\
\text { Type }\end{array}$ & \multicolumn{2}{|c|}{ Lighting (kWh) } & \multicolumn{2}{|c|}{ Heating (kWh) } & \multicolumn{2}{|c|}{ Cooling (kWh) } & \multicolumn{2}{|c|}{ Total (kWh) } \\
\hline IBE & 4287.0 & & 12.1 & & 36765.2 & & 41064.3 & \\
\hline IBE w/o R & 4350.3 & $+1.5 \%$ & 15.7 & $+30.1 \%$ & 34237.5 & $-6.9 \%$ & 38603.5 & $-6.0 \%$ \\
\hline IBE w/o $S$ & 4132.2 & $-3.6 \%$ & 4.6 & $-61.7 \%$ & 49299.1 & $+34.1 \%$ & 53435.9 & $+30.1 \%$ \\
\hline
\end{tabular}


Table 2

Control building's energy consumption in Washington, D.C.

\begin{tabular}{ccccccccc}
\hline $\begin{array}{c}\text { Simulation } \\
\text { Type }\end{array}$ & \multicolumn{2}{c}{ Lighting $(\mathrm{kWh})$} & \multicolumn{2}{c}{ Heating $(\mathrm{kWh})$} & \multicolumn{2}{c}{ Cooling $(\mathrm{kWh})$} & \multicolumn{2}{c}{ Total $(\mathrm{kWh})$} \\
\hline IBE & 4477.8 & & 12491.9 & & 13813.9 & & 30783.5 & \\
IBE w/o R & 4572.2 & $+2.1 \%$ & 13121.7 & $+5.0 \%$ & 12436.2 & $-10.0 \%$ & 30120.0 & $-2.2 \%$ \\
IBE w/o S & 4261.9 & $-4.8 \%$ & 9212.7 & $-26.3 \%$ & 21219.6 & $+53.6 \%$ & 34694.2 & $+12.7 \%$ \\
\hline
\end{tabular}


Table 3

Control building's energy consumption in Minneapolis, MN

\begin{tabular}{|c|c|c|c|c|c|c|c|c|}
\hline \multirow{2}{*}{$\begin{array}{c}\begin{array}{c}\text { Simulation } \\
\text { Type }\end{array} \\
\text { IBE }\end{array}$} & \multicolumn{2}{|c|}{ Lighting (kWh) } & \multicolumn{2}{|c|}{ Heating (kWh) } & \multicolumn{2}{|c|}{ Cooling (kWh) } & \multicolumn{2}{|c|}{ Total (kWh) } \\
\hline & 4572.1 & & 28228.7 & & 10756.4 & & 43557.1 & \\
\hline IBE w/o R & 4676.3 & $+2.3 \%$ & 28986.1 & $+2.7 \%$ & 9575.6 & $-11.0 \%$ & 43237.9 & $-0.7 \%$ \\
\hline IBE w/o S & 4309.8 & $-5.7 \%$ & 23504.1 & $-16.7 \%$ & 17580.1 & $+63.4 \%$ & 45394.1 & $+4.2 \%$ \\
\hline
\end{tabular}




\section{Table 4}

Control building energy consumption monthly results.

\begin{tabular}{cccccccccc}
\hline & \multicolumn{3}{c}{ Miami, FL } & \multicolumn{3}{c}{ Washington, D.C. } & \multicolumn{3}{c}{ Minneapolis, MN } \\
\hline Month & $\begin{array}{c}\text { IBE } \\
(\mathrm{kWh})\end{array}$ & $\begin{array}{c}\text { IBE } \\
\text { w/o R } \\
(\mathrm{kWh})\end{array}$ & $\begin{array}{c}\text { IBE } \\
\text { w/o S } \\
(\mathrm{kWh})\end{array}$ & $\begin{array}{c}\text { IBE } \\
(\mathrm{kWh})\end{array}$ & $\begin{array}{c}\text { IBE } \\
\text { w/o R } \\
(\mathrm{kWh})\end{array}$ & $\begin{array}{c}\text { IBE } \\
\text { w/o } \\
(\mathrm{kWh})\end{array}$ & $\begin{array}{c}\text { IBE } \\
(\mathrm{kWh})\end{array}$ & $\begin{array}{c}\text { IBE } \\
\text { w/o R } \\
(\mathrm{kWh})\end{array}$ & $\begin{array}{c}\text { IBE } \\
\text { wh } \mathrm{k} \\
(\mathrm{kWh})\end{array}$ \\
\hline Jan. & 1700.3 & $-9.4 \%$ & $+47.5 \%$ & 4826.2 & $+2.5 \%$ & $-14.7 \%$ & 9820.9 & $+1.3 \%$ & $-10.8 \%$ \\
Feb. & 1981.3 & $-9.0 \%$ & $+36.6 \%$ & 3146.4 & $+4.8 \%$ & $-20.4 \%$ & 5925.3 & $+2.7 \%$ & $-15.9 \%$ \\
Mar. & 2515.0 & $-9.3 \%$ & $+38.5 \%$ & 1629.5 & $+4.6 \%$ & $-6.4 \%$ & 3295.2 & $+5.2 \%$ & $-20.4 \%$ \\
Apr. & 3163.6 & $-7.6 \%$ & $+35.7 \%$ & 1258.7 & $-6.8 \%$ & $+35.6 \%$ & 2033.3 & $+1.7 \%$ & $-1.4 \%$ \\
May & 4049.8 & $-5.9 \%$ & $+27.3 \%$ & 2305.9 & $-9.4 \%$ & $+42.3 \%$ & 1791.1 & $-10.1 \%$ & $+48.9 \%$ \\
Jun. & 4484.7 & $-5.4 \%$ & $+21.8 \%$ & 3276.5 & $-8.0 \%$ & $+34.8 \%$ & 2659.2 & $-9.8 \%$ & $+44.7 \%$ \\
Jul. & 5036.9 & $-5.4 \%$ & $+21.8 \%$ & 3929.6 & $-7.3 \%$ & $+31.7 \%$ & 3515.4 & $-7.8 \%$ & $+34.9 \%$ \\
Aug. & 4504.5 & $-5.5 \%$ & $+23.2 \%$ & 3411.7 & $-7.7 \%$ & $+31.8 \%$ & 2464.8 & $-9.5 \%$ & $+46.6 \%$ \\
Sep. & 4328.3 & $-5.8 \%$ & $+21.6 \%$ & 2091.7 & $-9.2 \%$ & $+39.6 \%$ & 1614.7 & $-7.3 \%$ & $+38.8 \%$ \\
\hline Oct. & 3812.9 & $-6.6 \%$ & $+24.2 \%$ & 1002.0 & $-2.6 \%$ & $+30.4 \%$ & 1488.7 & $+4.6 \%$ & $-6.4 \%$ \\
Nov. & 2635.5 & $-6.8 \%$ & $+31.2 \%$ & 1655.3 & $+5.7 \%$ & $-16.9 \%$ & 4845.0 & $+2.2 \%$ & $-14.8 \%$ \\
Dec. & 1732.1 & $-8.7 \%$ & $+46.5 \%$ & 4575.9 & $+2.8 \%$ & $-18.0 \%$ & 8450.8 & $+1.1 \%$ & $-8.7 \%$ \\
\hline
\end{tabular}


Table 5

Cross regional comparison of reference building's energy consumption

\begin{tabular}{ccccccc}
\hline \multicolumn{2}{c}{ Regions/Cities } & IBE & \multicolumn{2}{c}{ IBE w/o R } & \multicolumn{2}{c}{ IBE w/o S } \\
\hline \multirow{2}{*}{ Midwest } & MN & 43557.1 & 43237.9 & $-0.7 \%$ & 45394.1 & $+4.2 \%$ \\
& CHI & 37673.1 & 37199.1 & $-1.3 \%$ & 40445.2 & $+7.4 \%$ \\
\hline \multirow{2}{*}{ Northeast } & BOS & 31909.0 & 31619.9 & $-0.9 \%$ & 33712.7 & $+5.7 \%$ \\
& NYC & 31658.1 & 31046.4 & $-1.9 \%$ & 35091.4 & $+10.8 \%$ \\
\hline \multirow{2}{*}{ West } & SF & 13377.5 & 12187.8 & $-8.9 \%$ & 21463.2 & $+60.4 \%$ \\
& LA & 19152.9 & 17098.0 & $-10.7 \%$ & 30180.9 & $+57.6 \%$ \\
\hline \multirow{2}{*}{ South } & HOU & 32526.6 & 30802.9 & $-5.3 \%$ & 41954.7 & $+29.0 \%$ \\
& MIA & 41064.3 & 38603.5 & $-6.0 \%$ & 53435.9 & $+30.1 \%$ \\
\hline
\end{tabular}




\section{Table 6}

Reference building's energy consumption in Perugia urban context (a)

\begin{tabular}{ccccccccc}
\hline Simulation Type & \multicolumn{2}{c}{ Lighting $(\mathrm{kWh})$} & \multicolumn{2}{c}{ Heating $(\mathrm{kWh})$} & \multicolumn{2}{c}{ Cooling $(\mathrm{kWh})$} & \multicolumn{2}{c}{ Total $(\mathrm{kWh})$} \\
\hline IBE & 2177.5 & & 19960.6 & & 600.1 & & 22738.1 & \\
IBE w/o R & 2240.7 & $+2.9 \%$ & 20908.7 & $+4.7 \%$ & 447.2 & $-25.5 \%$ & 23596.5 & $+3.8 \%$ \\
IBE w/o S & 1810.4 & $-16.9 \%$ & 17438.1 & $-12.6 \%$ & 2025.6 & $+237.6 \%$ & 21274.1 & $-6.4 \%$ \\
\hline
\end{tabular}


Table 7

Reference building's energy consumption in Perugia urban context (b)

\begin{tabular}{ccccccccc}
\hline Simulation Type & \multicolumn{2}{c}{ Lighting $(\mathrm{kWh})$} & \multicolumn{2}{c}{ Heating $(\mathrm{kWh})$} & \multicolumn{2}{c}{ Cooling $(\mathrm{kWh})$} & \multicolumn{2}{c}{ Total $(\mathrm{kWh})$} \\
\hline IBE & 25338.1 & 67799.4 & & 11200.6 & & 104338.0 & \\
IBE w/o R & 25641.4 & $+1.2 \%$ & 69036.1 & $+1.8 \%$ & 10167.3 & $-9.2 \%$ & 104844.8 & $+0.5 \%$ \\
IBE w/o S & 24015.4 & $-5.2 \%$ & 65526.4 & $-3.4 \%$ & 12877.0 & $+15.0 \%$ & 102418.8 & $-1.8 \%$ \\
\hline
\end{tabular}

